Material for Visual Education

By Betty M. B. Harris. Edited by G. Patrick Meredith. (Published for the Film Council.) Pp. 96. (London: Daily Mail School-Aid Department, 1947.) $2 s .6 d$.

A VISUAL aid may fail through some inherent defect; or the right aid may be used in the wrong place, in which case the fault lies with the teacher. Yet not wholly so, for in the absence of any comprehensive survey of sources of visual material the teacher has too often been obliged to rest content with what he knew was available.

The book under review can fairly claim not only to map out the main areas of visual provision but also, by an ingenious and practical system of indexes, to make everyman his own explorer. Thus the inquirer for, say, a filmstrip on Chinese art is led through successive summaries, each of which narrows his field of search, until he arrives at the address of the organisation most likely to meet his need.

This book will be much thumbed and deserves a more substantial binding. Regarded from the point of view of a work of reference, the appendix, which deals more generally with the theme of visual education and with the work at University College, Exeter, might well have awaited the separate and more detailed account which is promised in the text.

It is to be hoped that there will be future editions which will expand the work where necessary and keep it up to date. In which case, again for ease of reference, pages of advertisements should not be interspersed with the text. The pertinent reminder, in the Films Section, that "inclusion in a catalogue is no guarantee of merit", might well be transposed to the preface.

ERIo Lowe

They Live in the Sea

By Douglas P. Wilson. Pp. 128 (90 plates). (London and Glasgow: Wm. Collins, Sons and Co., Ltd., 1947.) 12s. $6 d$. net.

THIS book of most beautiful photographs cannot fail to delight. To the biologist it is fascinating, and to those with only a superficial interest in natural history, or little appreciation of natural beauty, it is a revelation. From such a collection it is difficult to select individual pictures for special mention. The most dramatic are the series showing a Portuguese man-of-war capturing and feeding upon a wrasse, and that showing a cuttle-fish securing a prawn after a first attempt successfully dodged by the prospective victim. But the author is not content with the dramatic only, and follows up the studies of Physalia with an excellent photomicrograph of nematocysts discharged and undischarged, and an enlarged view of the gastrozooids digesting the fish. No less striking are the studies of the strobilation and release of medusæ by the scyphistoma of Aurelia. Some of the most beautiful pictures are those of semi-transparent animals, where the author has been highly successful in showing the translucency of sea-anemones, alcyonarians, prawns, ascidians and larval forms. The text, avoiding technicalities and Latin names, gives a clear and accurate account of the animals portrayed in the plates. A short chapter deals with dredging and trawling; and any biologist who has worked at Plymouth during the last halfcentury will recognize with pleasure the characteristic portrait in Plate 25. From this author we expect outstanding pictures, and we are not disappointed.

L. Harrison MatThews

\section{Light, Vision and Seeing}

A Simplified Presentation of their Relationships and their Importance in Human Efficiency and Welfare. By Dr. Matthew Iuckiesh. Fourth printing. Pp. xiv $+323+16$ plates. (New York: D. Van Nostrand Co., Inc. ; London : Macmillan and Co., Ltd., 1946.) 25s. net.

$\mathrm{T}$ this book will be found a popular and readable account of numerous problems relating to lighting and vision. A large number of important psychological and physiological experiments carried out under the author's direction are reported in simple terms, with very clear diagrams illustrating the meaning of the results in a practical form. After reviewing the difficulties presented to the human eye by the needs of reading and innumerable everyday activities, the author proceeds to consider eyedefects, and the practical problems and history of artificial lighting. Then he studies the influence of various factors in making objects visible: intensity of illumination, relative size, brightness contrast, eye movements and the time required for seeing, visual acuity and its measurement by test charts. Later he considers the physiological effects of seeing, practical problems of lighting, various common illuminants, colour discrimination, glare and other important matters, including the relation of safety and efficiency to the ease of seeing. At the end of the book he includes answers to one hundred common questions about vision, light and colour.

The industrial psychologist and lighting engineer will find this book a mine of valuable information and practical help about problems of applied science as far as vision is concerned. R. W. PICKroRD

\section{Molds, Yeasts and Actinomycetes}

A Handbook for Students of Bacteriology. By the late Dr. A. T. Henrici. Second edition, by Dr. Charles E. Skinner, Dr. Chester W. Emmons and Dr. Henry M. Tsuchiya. Pp. xiv +409 . (New York : John Wiley and Sons, Inc. ; London : Chapman and Hall, Ltd., 1947.) 5 dollars.

A $\mathrm{S}$ a short and readable handbook for the many A different categories of student and research worker concermed with mycological problems, whether industrial or medical, this new edition of Henrici's well-known book should prove of real value. It is up to date-in so far as this is possible at a time when the whole subject is in a state of rapid advance, with the concomitant production of a vast new literature. Indeed, a more or less complete re-writing of the earlier edition has been necessary in order to do justice to the many exciting discoveries of the past decade. The aim, like that of the earlier edition, has been to provide bacteriologists with some of the knowledge which they ought to possess concerning other groups of parasitic and saprophytic microorganisms, that is, yeasts, moulds, and actinomycetes.

The result is a book which, within its set limits, should prove useful to many. The stress, of course, is on the medical and industrial applications of mycology. In fourteen chapters, a wide range of topics is discussed and admirably illustrated. These include general dissertations on the structure, classification and methods of study of moulds, yeasts, etc., and particular accounts of fungi causing diseases of man and animals, and of use in industrial fermentations, etc. Yeasts and actinomycetes are accorded a fairly full treatment, and a final chapter is devoted to antibiotic substances. 